\title{
Marine Power Distribution System Fault Location Using a Portable Injection Unit
}

\author{
K. Jia, T. Bi, B. Liu, E. Christopher D. W. P. Thomas and M. Sumner
}

\begin{abstract}
A portable injection unit for Active Impedance Estimation (AIE) is built and tested in a DC zonal marine power distribution system to provide useful information for system protection and restoration. The portable unit generates current "spikes" and injects them into the system once short circuit faults are detected (by measuring the system voltage drop). The faulted system impedance can be estimated by AIE and comparing the estimated impedance with the pre-calibrated value, the fault location can be determined. The proposed method does not rely on system fault transient information or communication from the remote-end measurement and offers fast and accurate fault location in DC marine distribution systems. The proposed method has been tested and validated on a 750V, 2 MW twin bus DC Commercial Test Facility with the system both de-energised and energised.
\end{abstract}

Index Terms-- fault location, marine distribution system, injections, active impedance estimation

\section{INTRODUCTION}

$\mathrm{T}$ The development of integrated electrical propulsion, the increase in high energy electrical loads and the widespread use of electronics are placing a heavy demand on the quality and survivability of modern marine power systems. Zonal distribution architectures can potentially be employed with a higher degree of power quality and a superior capability for fault ride-through than is presently available[1]-[4]. Reliable electricity power supply is guaranteed using sophisticated protection schemes that can detect and isolate the faulted sections within a prescribed short period of time.

DC power distribution systems offer advantages over AC systems including: less conversion stages and higher efficiency; simple interface for energy storage devices and paralleling connected generators; smaller size and weight of the cables and other distribution equipment and improved flexibility [11]-[13]. As a stand-alone distribution power system, the conventional over-current [5]-[7] and current differential [8]-[9] protection schemes are employed in the marine power system as a primary protection. However, when the over-current relay is utilized in such a small distribution system with very short cables (sometimes metal bars), it is difficult to adjust the covering areas without sacrificing the fault detection time. Faults occurring near the generators often

$\mathrm{K} \mathrm{Jia}$ and $\mathrm{T}$. Bi are with the North China Electric Power University, Beijing, China (e-mail: ke.jia@ncepu.edu.cn).

Edward Christopher, Dave Thomas and Mark Sumner are with the Nottingham, UK

This work was partially supported by 973 Program (2012CB215206) and the Fundamental Research Funds for the Central Universities (JB2014054 and JB2014002) leads to longer detection time [7]. Differential relay normally provides fast operations for internal faults and does not have to coordinate with neighbor relay settings. Communication is required within the differential protection scheme and this causes a potential problem to the system when communication fails. In modern DC marine distribution systems, low voltage buses are supplied from AC generators and controlled rectifiers. If the load current continuously exceeds the steady current limit, or exceeds the particular transient current limit level, the output voltage control can quickly change to a current control (or a overall power control) and reduces the output current to an accepted level, so that fault interruption problems associated with DC breakers can be reduced. One form of this control is called "fold-back" [10] and this brings more challenges to the traditional unit protection schemes that rely on the detection of the abnormal behavior of the system current.

Fault location methods which can provide the exact fault distance between the measurement units and the fault points have been considered as a primary/backup protection in power systems[14]-[22]. In marine power systems which have no exposed distribution cables it is difficult to remove or restore the faulted line sections without accurately knowing the fault position. Generally fault location schemes can be classified into two categories: based on impedance estimation ${ }^{[14]-[20]}$ and based on traveling waves [21][22]. Fault location schemes based on system impedance estimation have been developed for many years. In [14] and [15], Takagi proposed the singleended technique based on measured pre-fault and post fault information which does not require a communication channel but the fault location accuracy may be affected by the assumption that the system has lossless transmission lines. Double-ended schemes as described in [16], [17] present simple and robust fault location methods but a GPS based synchronization is required to produce accurate fault location results. In [18]-[20] fault location methods were investigated based on a system distributed parameter model which provided a higher accuracy compared with traditional impedance models (ignoring the shunt capacitance). However, the iteration calculation may bring more errors to the result considering the system noise and distortion and moreover a system with a non-linear load may not be suitable for this method. All the discussed impedance fault location methods utilize steady state calculations at the system frequency $(50 \mathrm{~Hz} / 60 \mathrm{~Hz})$. The cable or bus bar impedance of the ship power system at low frequency is too small for fault classification. Traveling wave method has been developed in the distribution level [21]-[22] which has been proved to be 
able to offer fast and accurate fault location on transmission lines. This method, however, requires high performance data acquisition units and for accurate fault location in a distribution system, with cable lengths of a few metres, requires transducer bandwidth and sampling frequency of over $1 \mathrm{GHz}[32]$.

Fault location methods based on injections are usually employed for phase to ground faults in compensated or ungrounded distribution systems [28]-[31]. Transients and/or sinusoidal injection was performed through extra voltage transformers [28][29] or by the short-circuit of the compensation coil ${ }^{[30][31]}$. By tracing the injected signal, the faulted line is detected. However, these methods require multipoint measurements for the signal tracking and can only distinguish the faulted line of a radial network but not the exact fault distance due to the line shunted capacitive current. The system has to be modified for this kind of injection and this will limit its application.

This paper introduces a portable fault location unit based on high frequency Active Impedance Estimation (AIE) and can be used in the modern marine power distribution system. Triangular current "spikes" are injected into the system once the system voltage drop, caused by short circuit faults, is detected. The estimated high frequency impedance value is then compared with the pre-calibrated system impedance value to locate the fault positions. This fault position information can be used in the backup protection scheme and also brings convenience for fault isolation and system restoration.

The paper is organized as follows. An overview of the algorithm is given in section II. The signal processing methods are described in section III. The portable unit and experimental set up are described in section IV and the testing results (both de-energised and energised) from the experimental system are presented in section V. Finally the conclusions are given in section VI.

\section{ALGORITHM OVERVIEW}

Different from the conventional distribution power system faults (more than $80 \%$ faults are phase to earth faults and a large amount of them are temporary faults), most of the short circuit faults in the Marine Power Systems (MPS) are phase to phase and phase to earth permanent faults with a small fault resistance (comparable to the cable impedance) caused by insulation failure. Once a fault is detected, the injection unit is controlled to produce a triangular current transient into the system. A simplified diagram of the injection unit is given in Fig. 1. Since most of the short circuit faults within the MPS have very low fault impedances, the measured system impedance from the injection point is dominated by the fault loop impedance (the bus bar or cable impedance from the injection point to the fault point) characteristics. Injecting positions are selected to primarily provide protection to the system generators and important loads. For stand-alone injections (as discussed in this paper), the injection units are installed close to system generators to guarantee the safety of the voltage supply. For injectors embedded in converters, the injection points can be at the both the supply and the load converters.

The injection is performed by a controlled grid connected bridge circuit with a DC link capacitor through a coupling inductor as shown in Fig 1.a. The ideal injection voltage $\left(\mathrm{V}_{\text {Inj }}\right)$ and the resultant injection current $\left(\mathrm{I}_{\text {Inj }}\right)$ through the coupling inductor are shown in Fig.1b. A step voltage waveform is created by controlling the operation of the two IGBT switches and is applied to the coupling inductor resulting in a triangular current. This current is then injected into the system through the Point of Common Coupling (PCC).

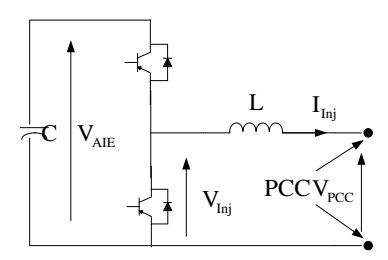

a)

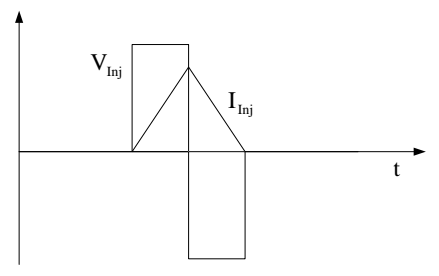

b)
Fig. 1 Injection unit and its injection voltage and current, a)Simplified injection unit diagram , b)injection waveforms

The voltage and current are recorded and processed by a digital signal processor with the following procedure: Blackman [23] windowing; Zero padding; Fast Fourier Transform (FFT); Impedance calculation $(\mathrm{Z}=\mathrm{FFT}(\mathrm{V}) / \mathrm{FFT}(\mathrm{I}))$ and curve fitting.

The estimated impedance results are compared with the deenergised calibration results to indentify the fault locations. The algorithm for fault distance estimation can be presented in 5 steps: 1) The measured voltage and current are Blackman windowed using (1), to remove the influence of edges at the start and end of the recorded data. This will create a smooth curve, and this data is then processed with an FFT.

$$
w(n)=0.42-0.5 \cos \left(\frac{2 \pi n}{N-1}\right)+0.08 \cos \left(\frac{4 \pi n}{N-1}\right)
$$

In (1), $\mathrm{N}$ is the length of the Blackman window. The edge of recorded data (for a rectangular window) will cause waveform distortion if the data is directly transformed to frequency domain. The Blackman window which smoothes the recorded data edges to zero will eliminate this effect and also provide a good condition for data zero padding; 2) Zero padding doesn't add any information to the original data but increase the length of the data with zeros. This provides a better frequency resolution and will improve the fault distance estimation accuracy accompanied with the curve fitting process; 3) The padded voltage and current data is transformed into the frequency domain by the Fourier Transform:

$$
F(x(n))=\sum_{n=0}^{L-1} x(n) e^{-(2 \pi j n k \Delta t / L)}
$$

where $\mathrm{n}$ is the sample index, $\mathrm{k}$ is the frequency index and $\Delta t$ is the sample period. This can be made more efficient by using the FFT where only the frequency steps of $L / \Delta t$ are taken (k is an integer) and it is assumed that the signal is infinitely repeating or has finite extent [24]-[25]; 4) The system impedance is calculated in the frequency domain using (3) and the reactance part (dominant part) is used for fault distance calculation. 


$$
X(f)=\frac{\operatorname{imag}(F(v(t)))}{\operatorname{imag}(F(i(t)))}
$$

5) Due to steady state distortion in the system and the presence of background measurement noise, the estimated reactance waveform in the frequency domain has some oscillation. A least square curve fitting which provides a fitted straight line to given points in frequency domain is applied to the impedance results for a better accuracy [26]. In order to utilize a linear least squares curve fitting to a $\mathrm{n}$ points sampled data, the vertical offset $R^{2}$ of $n$ points is defined as:

$$
R^{2}=\sum_{i=1}^{n}\left[y_{i}-\left(a+b x_{i}\right)\right]^{2}
$$

where $x$ is the frequency information and $y$ is the corresponding reactance value. Assuming the fitted line is $y=a+b x$. In order to minimize the deviations:

$$
\begin{aligned}
& \frac{\partial\left(R^{2}\right)}{\partial a}=-2 \sum_{i=1}^{n}\left[y_{i}-\left(a+b x_{i}\right)\right]=0 \\
& \frac{\partial\left(R^{2}\right)}{\partial b}=-2 \sum_{i=1}^{n}\left[y_{i}-\left(a+b x_{i}\right)\right] x_{i}=0
\end{aligned}
$$

Solving the (5) and (6), $a$ and $b$ can be calculated using (7)

$$
\left[\begin{array}{l}
a \\
b
\end{array}\right]=\left[\begin{array}{cc}
n & \sum_{i=1}^{n} x_{i} \\
\sum_{i=1}^{n} x_{i} & \sum_{i=1}^{n} x_{i}^{2}
\end{array}\right]^{-1}\left[\begin{array}{c}
\sum_{i=1}^{n} y_{i} \\
\sum_{i=1}^{n} x_{i} y_{i}
\end{array}\right]
$$

Then the estimated line reactance results (from the fitted line) are compared with the pre-calibrated values to calculate the fault distance. The fault distance information can then be used to inform the protection algorithms.

\section{SIGNAL PROCESSING}

Online high frequency impedance estimation has to deal with not only the system high frequency noise and distortion but more importantly the "edge effect" of the captured data segments when a rectangular window is applied. Once the injection has taken place after a fault is detected, the captured injected voltage and current data segment includes both the steady state and the injection transient waveform. Directly applying FFT to this finite data, the results will be influenced by the frequency leakage and the "edge effect". This can be demonstrated by applying a step current (from $0 \mathrm{~A}$ to $1 \mathrm{~A}$ ) injection to an energised RLC circuit as shown in Fig.2 and the measured current $\left(\mathrm{I}_{\text {measured }}\right)$ and voltage $\left(\mathrm{V}_{\text {measured }}\right)$ at the Point of Measurement (POM).

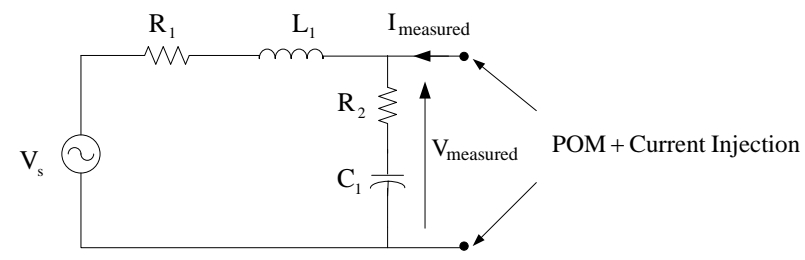

Fig. 2 Test circuit for impedance measurement techniques: $R_{1}=0.4 \Omega$, $\mathrm{L}_{1}=1.15 \mathrm{mH}, \mathrm{R}_{2}=0.4 \Omega, \mathrm{C}_{1}=100 \mu \mathrm{F}$ and $\mathrm{Vs}=10 \mathrm{~V}$ (peak).

The measured injection transients are shown in Fig.3. The 40ms (two cycles) data include both steady state and the injected transient information (The measured voltage waveform contains both the steady state voltage $\left(\mathrm{V}_{\mathrm{s}}\right)$ and the transient response caused by the step current injection).
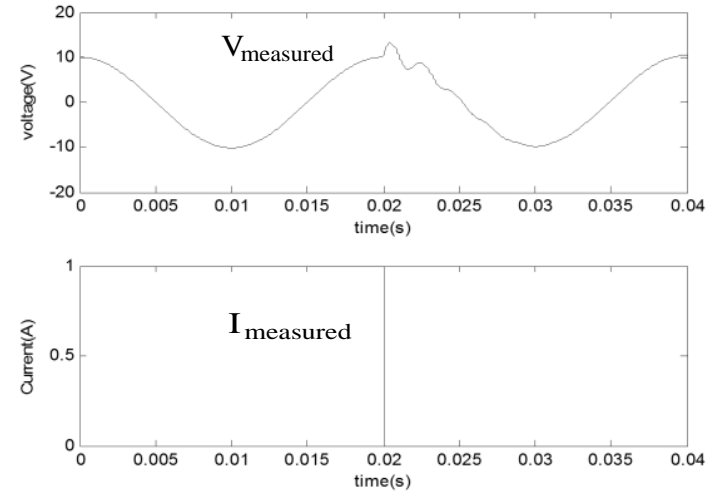

Fig.3 Measured current and voltage waveforms

The measured voltage and current data are then transformed into the frequency domain for the system impedance calculation. As a comparison, the Continuous Wavelet Transform (CWT) is used as well as FFT for the impedance estimation. The CWT is known as a more effective data processing tool than the FFT when dealing with nonperiodic signals due to the fact that it uses a special series of non-sinusoidal wavelets. The selected mother wavelets act as band pass filters and offer a smooth curve in frequency. A Morlet wavelet ${ }^{[27]}$ is chosen and described by (8):

$$
\varphi(x)=\frac{1}{\sqrt{\pi f_{b}}} e^{j 2 \pi f_{c} x} e^{\frac{-x^{2}}{f_{b}}}
$$

where the bandwidth frequency $f_{b}$ is $10 \mathrm{~Hz}$ and the centre frequency $f_{c}$ is $2 \mathrm{~Hz}$ to emphasize the accuracy of the results in the high frequency range.

Directly applying the FFT and the CWT to the data shown in Fig.3, both methods suffer from the "edge influence". However, the CWT produces much better accuracy in the high frequency range (Fig.4.c and Fig.4.d) where the FFT gives large errors as shown in Fig.4.a and Fig.4.b. Since the CWT provides frequency results that refer to the data time domain information, in a time-frequency map (CWT results) as shown in Fig.5, it is clear that the "edges" of the data segment contains high frequency information which is comparable to the injection transient in the frequency domain.

The three-dimensional plot (CWT results) of the step current waveform which consists of time, frequency and energy coefficient (abs value of the CWT) is shown in Fig.5. It is clear that the edge (at $0.04 \mathrm{~s}$ in time) generates energy in the frequency domain as well as the step transient (at $0.02 \mathrm{~s}$ ). The CWT can distinguish the frequency energy information from different time scale in higher frequency range (above $1 \mathrm{kHz}$ in this case). However, FFT sums and averages all the same frequency information through out the time domain. A time domain Blackman window can smoothly reduce the edges of the data segment to zero and greatly increase the accuracy of the FFT when dealing with transients that are captured in an energised system.

The CWT offers relative smooth but not necessarily very accurate results in the frequency in a noisy system due to its filter function of the mother wavelet. It is not suitable to use further curve fitting if the waveform has oscillation (caused by noise or system distortions) in the frequency domain. One of main reasons for the CWT being frequently used dealing with high frequency transients rather than FFT, is that it has 
selectable mother wavelets that can act as filter and reduce the influence of data "edges". However, this filtering function is not as good as adding a time domain window and this is especial true for a relative lower frequency impedance calculation.
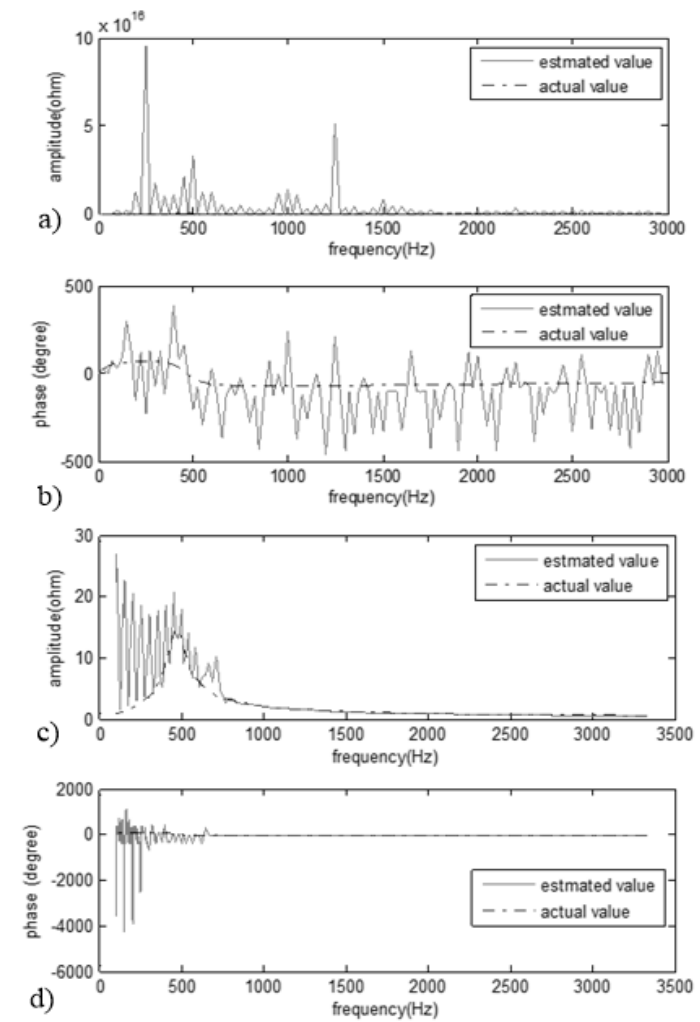

Fig.4 Estimated impedance results in the frequency domain a) amplitude results from FFT b)phase results from FFT c)amplitude results from CWT d)phase results from CWT

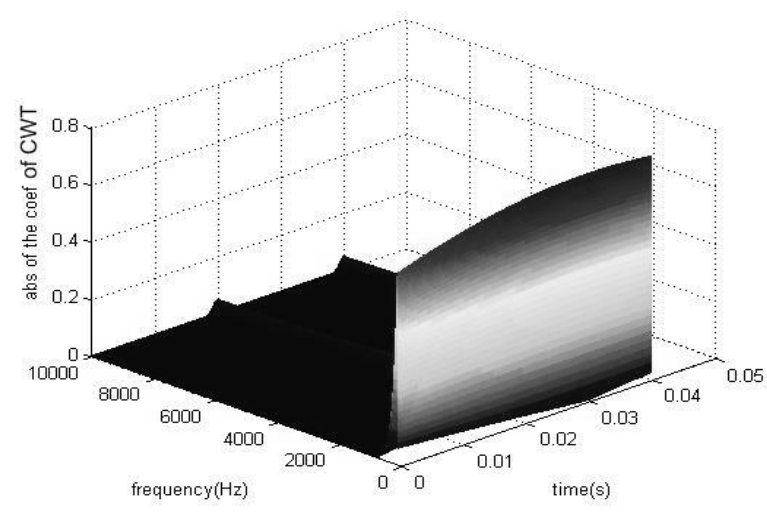

Fig.5 3D plot of the step current after processed with the CWT

For practical reasons, FFT is much more suitable for online fault location using a DSP processor as they often contain features specifically for FFT processing; and the FFT data processing time is much shorter than CWT for dealing with the same amount of data. The Blackman windowed FFT is therefore adopted in this paper.

\section{EXPERIMENTAL SETUP}

The portable injection unit was build and tested at the University of Nottingham. It was then used as a fault location unit and tested on a 2MW Commercial Test Facility (CTF).

\section{A. Portable injection unit}

As shown in Fig.6, the portable injection unit consists of a DSP/FPGA board, an isolation transformer, a variac, a diode rectifier, DC link capacitors, an IGBT $\mathrm{H}$ bridge, transducers, connectors and cables.

The injection unit is fed from a single phase $230 \mathrm{~V}$ AC supply utility through an isolation transformer. The variac and diode rectifier are used to provide DC voltage up to $1200 \mathrm{~V}$ to charge the DC link which employs two $2200 \mu \mathrm{F}$ capacitors (600V DC rated) in a series connection. For energised test, the highest test voltage for the system is $750 \mathrm{~V} \mathrm{DC}$ and the DC link voltage has to be higher than that to prevent the system current flowing back to the injection unit through the paralleled diodes in the IGBT $\mathrm{H}$ bridge. Note that in future versions the bus interface $\mathrm{H}$ bridge power converter using a boost mode of control could charge the DC link instead.

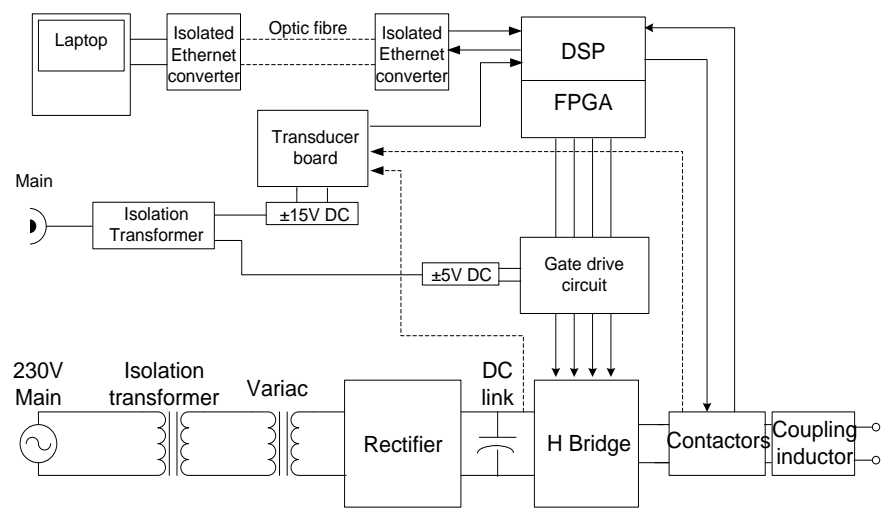

Fig.6 Schematic diagram of the portable injection unit

The $\mathrm{H}$ bridge output voltage feeds through a $4.8 \mathrm{mH}(40 \mathrm{~A}$ rated) inductor to generate the desired triangular injection current. The contactors are controlled to be switched on during the test and switched off when the injection is finished. Voltage and current transducers are located in the contactor circuit to measure the injection current and the system voltage response. The power supply for the transducers has an input of $115 \mathrm{~V}$ and two outputs of $+15 \mathrm{~V} / 2.4 \mathrm{~A}$ and $-15 \mathrm{~V} / 1.5 \mathrm{~A}$. This power supply is supplied by an isolated transformer. Digital Signal Processing (DSP) used in the injection system is the Texas instrument TMS320c6713. It is programmed with the fault location algorithm and the control algorithm for the $\mathrm{H}$ bridge. The field-programmable gate array (FPGA) acts a signal I/O for the DSP. It gives a $50 \mathrm{kHz}$ sampling frequency and a 12 bit resolution. This sampling frequency can provide results with good SNR (signal to noise ratio) in the interested frequency range and also is within the data processing limitation of the DSP

The control equipment includes two laptops: one located close to the injection equipment (host) and one used remotely from it, by the operator, in a safe position. The communication between the host laptop and the remote laptop is realized using isolated Ethernet converters. The host laptop is located outside of the room where the testing equipment is running.

\section{B. Commercial test facility}

The DC test facility has two buses: the port bus and the starboard bus and these two buses can be connected with a bus 
connector and circuit breakers as shown in Fig.7. DC voltages of both buses are converted from different AC sources. The port bus is fed from a $0.5 \mathrm{MW}$ main and the transformer output voltage is $440 \mathrm{~V} / 50 \mathrm{~Hz}$. The starboard bus is supplied by a $1.5 \mathrm{MW}$ diesel generator and the transformer second side voltage is $440 \mathrm{~V} / 60 \mathrm{~Hz}$. Both $\mathrm{AC}$ voltages are converted to $\mathrm{DC}$ by rectifiers with foldback control loops and then the DC (750V rated) voltage is fed to the main distribution circuit using a LC low pass filter. The configuration of the two buses is identical. Each bus contains 7 circuit breakers and can be classified into three zones.

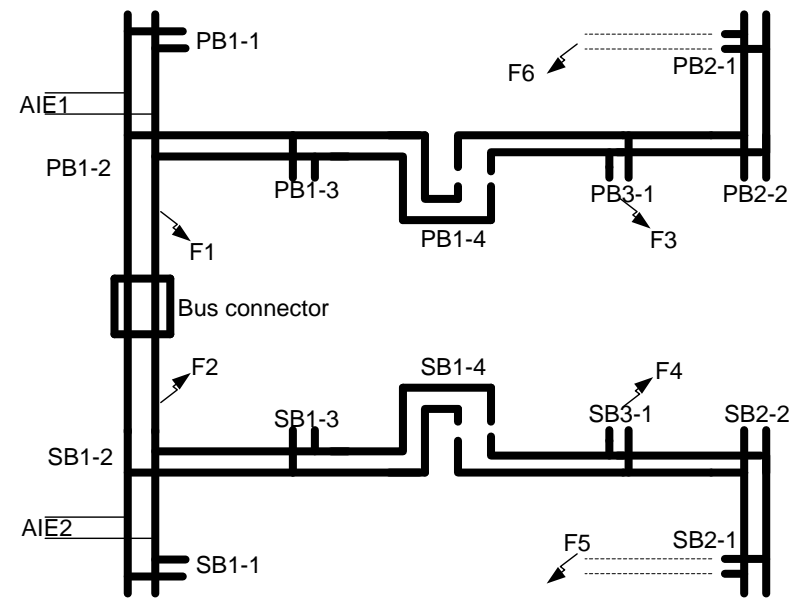

Fig.7 The configuration of Buses of the commercial testing facility

As shown in Fig.7, the first zone of the port bus has four breakers: PB1-1(supply breaker), PB1-2(bus connection breaker), PB1-3(load breaker) and PB1-4(bus tie breaker). The zone two has 2 load breakers (PB2-1, PB2-2) and zone three has one load breakers (PB3-1). PB1-2 and PB1-4 are closed during healthy operation and can be selected open according to different fault locations to guarantee only the faulted section is isolated and the rest of the system is not influenced. Each bus has four load breakers which are used to connected selectable loads to the bus. Common loads are directly connected to PB2-1 through converters with long cables $\left(160 \mathrm{~mm}^{2}-200 \mathrm{~mm}^{2}\right)$. Once a fault is detected on either of the buses, the important loads are disconnected from both buses and an energy storage system is then used to supply these loads for a short period. These loads are re-connected to the healthy bus when faulted section has been isolated and the bus voltage returns to the rated value. For the tests on a deenergised system, six different fault locations have been selected: at the bus connection breakers (F1 and F2), at the interface of breakers (F3 and F4) and at the end of the long cables (F5 and F6). The "faults" are created using a short copper bar with negligible fault impedance. Two injection points are selected (close to the supply breakers) to provide comparable test scenarios.

\section{RESULTS OF THE TESTS}

The aim of the tests undertaken at the CTF site was to demonstrate that portable Active Impedance Estimation (AIE) based unit could be used estimate fault location within an experimental system containing equipment which will be found in future DC marine power systems and at realistic power levels. The experiment tests include both on a de- energised system and an energised system. The de-energised tests give confidence that the injection method is able to distinguish faults in different areas of the system for variable system configuration and also provide reference value the energised tests. The energised tests validate that the proposed method works in an energised system and can provide system fault location information during a fault with a good accuracy.

\section{A. Results of the de-energised tests}

Fig.7 shows a configuration diagram for the DC test facility and it also shows the fault locations to be used (labeled F1-F6) and the two injection locations for the AIE equipment itself when the system is de-energised. The port and starboard distribution boards consist of solid copper bars and switchgear contained within an equipment cabinet which was closed throughout the tests for safety. Faults F1 and F3 are used specifically to determine whether fault locations can be determined within the port distribution board, measured either from the local injection AIE1 or from the remote injection AIE2. Similarly faults F2 and F4 are used to determine whether fault locations can be determined within the starboard distribution board measured either from locations AIE2 or AIE1. Fault locations F5 and F6 are imposed at the end of lengths of cable, some distance from the distribution boards. These tests should show significant differences in the estimated impedance. The AIE injection waveforms for one particular fault seen from AIE1 are presented in Fig.8.

The triangular voltage and current waveforms are recorded with $50 \mathrm{kHz}$ sampling frequency $/ 8 \mathrm{~ms}$ window and transformed into frequency domain. The line impedance between the injection point and the fault point is estimated using the signal processing method described in Section III. Compared with the real part, the estimated reactance shows good accuracy and increases linearly with frequency. In the frequency range of interest (less than $2 \mathrm{kHz}$ ), the system impedance (cables and bus bars) is dominated by reactance (as shown in Fig.8 e and f, the reactance is much larger than the resistance) and the measured resistance can be easily influenced by measurement noise. Only the reactance measurement is used for the proposed fault location method. The inductance value derived from the imaginary part is $21 \mu \mathrm{H}$.
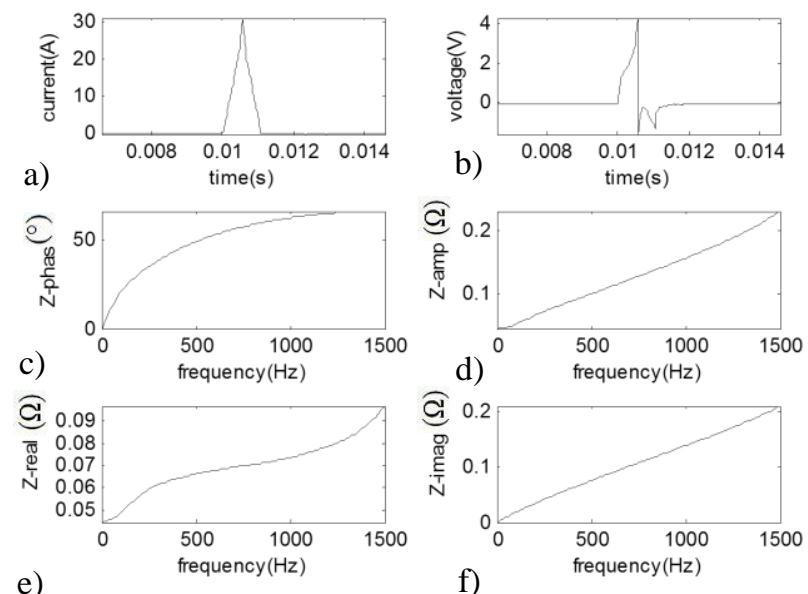

Fig.8 The estimated result from AIE1 for F5 a)injection current b)injection voltage c)impedance phase d) impedance amplitude e)real part f)imaginary part 


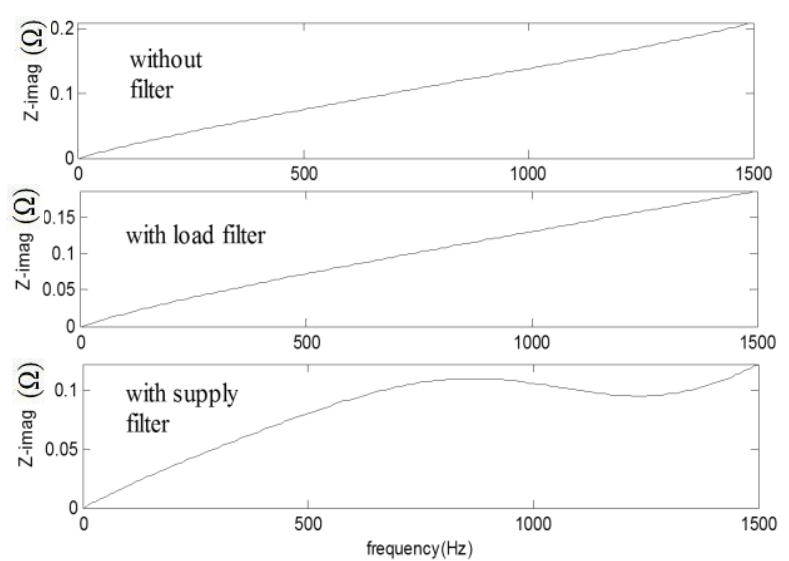

Fig.9 The estimated reactance from AIE1 for F5 under different filtering situations

The reactance result from Fig. 8 is derived without connecting the system supply filter and the load filter. The influence of system filters on the reactance calculation is shown in Fig.9.

The de-energised tests were repeated for F5 with load filters connected and then with the supply filters connected. As a comparison, three reactance results are plotted together. The load filters which are used to remove frequencies associated with pulse-width modulation of power converters have little influence on the estimated reactance as their resonant frequency is outside of the frequency range considered for AIE. Also, due to the buffering resistance (about $1 \Omega$ ), the load filter path shows a relatively large impedance (compared with the fault loop impedance) and little injection current flows through this path. Conversely, the filters on the supply side significantly distort the waveform in the frequency range between $800 \mathrm{H}$ to $1500 \mathrm{~Hz}$ : they have a much lower resonant frequency compared to the load filters, to attenuate the $300 \mathrm{~Hz}$ ripple component at the output of the controlled rectifier. However, even though the presence of the supply filters brings a large distortion to the reactance waveform above $800 \mathrm{~Hz}$, the value below $800 \mathrm{~Hz}$ can still be used and gives a similar inductance results to the one without filters connected (errors are less than $1.2 \%$ for repeated tests).

The estimated inductance value (derived from the reactance results) for different fault locations (F1-F6 in Fig.7) seen from two separate AIEs which are connected at the supply end of each bus are shown in Table I and Table II.

TABLE I

De-energised system test results derived from AIE1

\begin{tabular}{|l|l|l|l|c|}
\hline \multicolumn{5}{|c|}{ bus inductance derived from AIE1 $(\mu \mathrm{H})$} \\
\hline & Test1 & Test2 & Average & Errors $(\%)$ \\
\hline F1 & 6.128 & 6.284 & 6.206 & 1.257 \\
\hline F2 & 6.605 & 6.607 & 6.606 & 0.015 \\
\hline F3 & 7.372 & 7.368 & 7.370 & 0.027 \\
\hline F4 & 9.574 & 9.565 & 9.570 & 0.047 \\
\hline F5 & 24.520 & 24.160 & 24.340 & 0.740 \\
\hline F6 & 22.470 & 21.950 & 22.210 & 1.171 \\
\hline
\end{tabular}

The results are derived under the situation that all the filters (both supply and the load filters) are connected. All the results from AIE injections are compared with the ones derived from a commercial impedance analyser (only suitable for de-energised system) and the difference is small (within $2 \%)$.

TABLE II

De-energised system test results derived from AIE2

\begin{tabular}{|c|c|c|c|c|}
\hline \multicolumn{5}{|c|}{ bus inductance derived from AIE2 $(\mu \mathrm{H})$} \\
\hline & Test1 & Test2 & Average & Errors(\%) \\
\hline F1 & 6.460 & 6.684 & 6.672 & 0.180 \\
\hline F2 & 5.983 & 6.121 & 6.052 & 1.140 \\
\hline F3 & 9.562 & 9.548 & 9.555 & 0.968 \\
\hline F4 & 7.351 & 7.210 & 7.281 & 0.073 \\
\hline F5 & 23.270 & 23.970 & 23.620 & 0.968 \\
\hline F6 & 21.660 & 21.980 & 21.820 & 1.482 \\
\hline
\end{tabular}

For each fault location, two tests are carried out to demonstrate that the error of deviation is small and can be ignored. It is clear that for both injections the fault in different zones (on the buses and the cables) show a clear difference in the estimated inductance value. Results shown in both tables include the $10 \mathrm{~mm}^{2}$ cable inductance that connects the AIE to the injection point on the bus bar. The actual bus bar shows very small inductance and faults on cables (F5 and F6) give much larger inductance value than those on the bus bars. The bus bar inductance is presented in Table III using the difference of the two fault location results. TABLE III

Bus bar inductance value derived from both side injections during de-energised tests

\begin{tabular}{|c|c|c|}
\hline \multicolumn{3}{|c|}{ Bus bar inductance from AIE1 $(\mu \mathrm{H})$} \\
\hline F3-F1 & F2-F1 & F4-F2 \\
\hline 1.184 & 0.400 & 2.964 \\
\hline \multicolumn{3}{|c|}{ Bus Bar inductance from AIE2 } \\
\hline F4-F2 & F1-F2 & F3-F1 \\
\hline 1.229 & 0.420 & 3.083 \\
\hline
\end{tabular}

The test facility's copper bus bars (positive and negative phases) are separated by a thin PVC insulator (1.5mm width). The practical inductance between two layer copper bus bars can be approximated as:

$$
L=31.9(l) d / w \text { nano Henries }
$$

where $l$ is the length of the conductor, $d$ is the dielectric thickness and $w$ is the conductor width in inches

The approximated ideal inductance value of the bus bars is less than 100nH for each section (zone) and the estimated inductance value is dominated by the circuit breakers layout as shown in Fig.10.

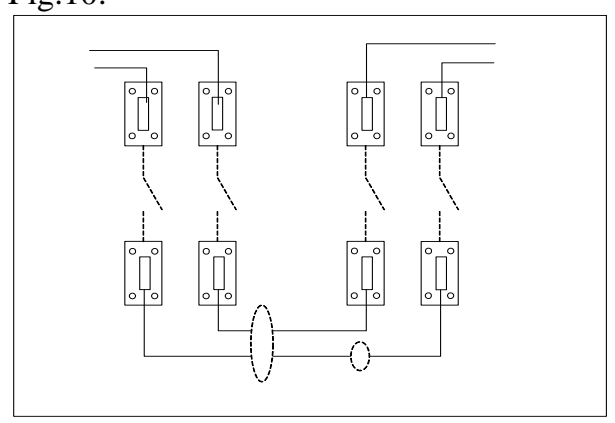

Fig.10 Configuration of applied circuit breaker

The breaker (800A, SACE E1 model from ABB) has 8 connectors and 4 switches, as shown in Fig.10. Four switches are triggered by the same signal. The bottom 4 connectors are 
connected by two bus bars and there is one common mode and one differential mode current transducer on each of the buses. The top 4 connectors connect the input and output two phases of the breaker. Except for the supply breakers (whose inputs are connected to cables) and the load breakers (whose outputs are connected to cables), both input and output connectors of the breakers are connected with copper bus bars.

The distance between the two bus-bar poles (on each pair of connectors) is about $95 \mathrm{~mm}$. For each two connectors, the input/output bus bar is about $200 \mathrm{~mm}$ in length. According to (9), this $200 \mathrm{~mm}$ length bus bar will have an inductance of $335 \mathrm{nH}$. Each breaker has four pairs for this connection and this presents an inductance of $1.34 \mu \mathrm{H}$. The estimated inductance value as shown in Table III matches this ideal calculation. For example, seen from AIE1, the result of "F3F1" includes one circuit breaker and this is much smaller than the measurement of "F4-F2" which includes two breakers. Faults on bus bars in different zones of the test facility which are separated by circuit breakers can be easily distinguished by the difference in the estimated inductance value even taking into account the influence of the injection cable, as shown in Table I and Table II.

\section{B. Results of the energised tests}

The tests were carried out in an energised system where the faults are triggered and the on-line fault location is performed through remote control. Each test was made with the system energised at $750 \mathrm{~V}$ and only AIE1 is performed. The trigger for the tests (i.e. the indication of a fault) is when the measured bus voltage drops below 500V. The first injection takes place $50 \mathrm{~ms}$ after this trigger. This measurement is made whilst the bus voltage is changing as part of the "foldback" process. The second injection is made $260 \mathrm{~ms}$ after the trigger and occurs when the bus voltage is close to zero and the supply current is controlled to a small value (about 10A). When the injection is made when the bus voltage is close to zero (with a $260 \mathrm{~ms}$ delay), the estimated results from AIE on an energised system are very similar to the results derived from the de-energised tests. However, when the injection is made during the bus voltage transient, as shown in Fig.11, there is distortion in the low frequency response. By restricting the frequency range used for AIE estimation to between $400 \mathrm{~Hz}$ and $800 \mathrm{~Hz}$ the reactance value can still be calculated consistently as shown in Table IV.

Fig.11 shows the typical energised test results for F5 seen from AIE1. As expected, the measured voltage waveform contains oscillation caused by the "foldback" control and the injection response. Compared with the injection transient the foldback distortion is small and most of the high frequency error (above $800 \mathrm{~Hz}$ ) in the estimated reactance is generated by the supply filters as discuss before. The low frequency abnormal behavior of the estimated impedance waveform is caused by the Blackman windowing. Both the real and the imaginary parts of the impedance are incorrect within the low frequency range (below $400 \mathrm{~Hz}$ ).

The resistance part which has a small actual value is more vulnerable to the windowing influence and shows a much larger error in Fig.11.
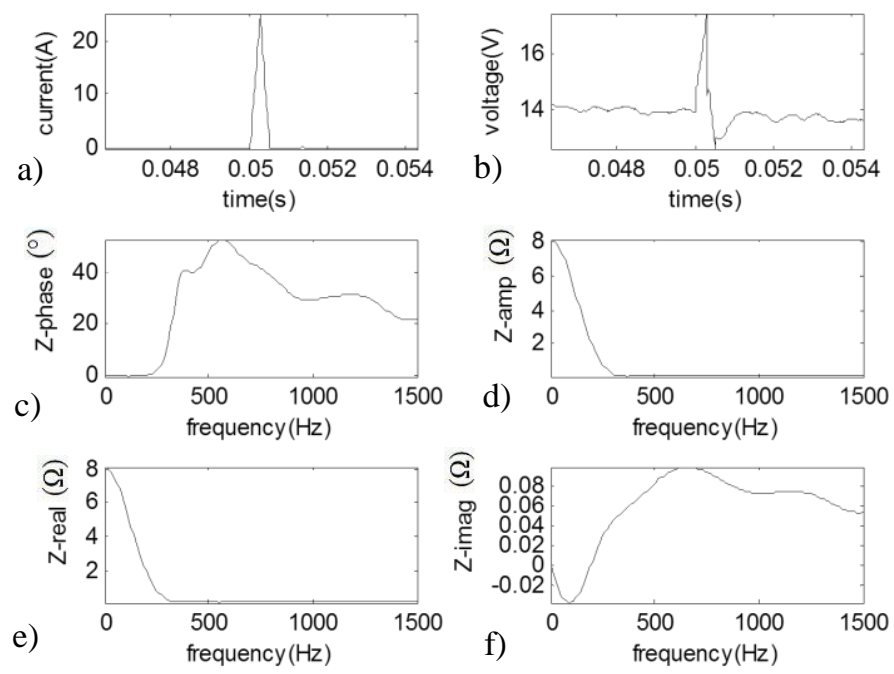

Fig.11Estimated impedance from the first injection for a fault at F5 with the system energized

a)injection current b)injection voltage c)impedance phase d) impedance amplitude e)real part f)imaginary part

During the energised tests, the supply filters of the test facility are connected, and the high frequency (above $800 \mathrm{~Hz}$ ) attenuation is mainly due to the effects of these filters. The ripple within the high frequency range was caused by the distortion of the voltage waveforms (Fig.11 b) which were produced during the "foldback" control. Although the waveforms are more distorted compared with the results from de-energised tests (Fig.8), a relatively good results can still be derived by selecting the suitable frequency range $(400 \mathrm{~Hz}$ to $800 \mathrm{~Hz}$ ). For energised tests, only three fault locations are selected and compared with the de-energiesd results, the errors as shown in Table IV are acceptable. TABLE IV

Inductance measured from AIE1 during the energised test

\begin{tabular}{|c|c|c|c|c|c|}
\hline \multicolumn{6}{|c|}{ inductance derived from AIE1 $(\mu \mathrm{H})$} \\
\hline & $\begin{array}{c}\text { Test1 } \\
(50 \mathrm{~ms})\end{array}$ & $\begin{array}{c}\text { Test2 } \\
(260 \mathrm{~ms})\end{array}$ & $\begin{array}{c}\text { De- } \\
\text { energised }\end{array}$ & $\begin{array}{c}\text { Errors of } \\
\text { Test1 }(\%)\end{array}$ & $\begin{array}{c}\text { Errors of } \\
\text { Test2(\%) }\end{array}$ \\
\hline F4 & 9.80 & 9.76 & 9.57 & 2.40 & 1.99 \\
\hline F5 & 23.74 & 24.77 & 24.34 & 2.46 & 1.76 \\
\hline F6 & 21.63 & 22.61 & 22.21 & 2.62 & 1.80 \\
\hline
\end{tabular}

Once faults occur and the system voltage drop is detected, the system "foldback" control starts and the fault current is controlled to a very low value $(10 \mathrm{~A})$ within $300 \mathrm{~ms}$. This brings a great challenge to the over-current and differential protections. However, as shown in the Table IV, the AIE fault location method offers good accuracy (less than 3\% error compared with the calibrated value) within a short period of time $(50 \mathrm{~ms} / 260$ after fault occurs). The injection which takes place during the fault transient $(50 \mathrm{~ms})$ gives a slightly larger error than the results of Test 2 which starts when the "foldback" effectively controls the system voltage to a value close to zero. The injection time can be selected according to requirement of the system fault location speed and accuracy when employed to a marine power distribution system. 


\section{CONCLUSIONS}

A fault location scheme based on active impedance estimation and can be utilized in a modern DC marine power distribution system is proposed. The method can be implemented with a portable injection unit that consists of simple power electronic components which are able to produce a short period (less than $1 \mathrm{~ms}$ ) and low current (less than 20A) injection into the system. Tests on both a deenergised and energised system have been carried out on a $750 \mathrm{~V}, 2 \mathrm{MW}$ twin bus DC commercial test facility. The results show that the proposed fault location method offers good accuracy regardless of the influence of the system filters and the fault current limiting control. Although the demonstrator bus bars have a low inductance value AIE is able to distinguish faults in different zones of the buses when the inductance of the circuit breaker and its complicated path is included in the assessment. Compared with AC system injection methods which require a system modification such as adding an extra voltage transformer or a short-circuit of the compensated earth, the proposed "portable" injection method can be directly connected to the system and/or embedded in the design of a shunt active filter without requiring any physical reconfiguration of the system. This real-time, fast and accurate fault location method can provide useful information for protection and system restoration. It can help with the correct operation of over-current protection which depends on measurement of the faulted current in the modern marine power system where fault current is limited by the "foldback" control.

\section{REFERENCES}

[1] T. Ericsen, N. Hingorani, and Y. Khersonsky, "Power electronics and future marine electrical systems," IEEE Trans. Industry Applications, vol.42, pp. 155-163, July. 2006.

[2] M. Baran and N. Mahajan, "System reconfiguration on shipboard DC zonal electrical system," in Proc. 2005 IEEE Electric Ship Technologies Symposium Conf, pp. 86-92.

[3] E. Christopher, M. Sumner, D. Thomas, X. H. Wang, and F. Wildt, "Fault location in a zonal DC marine power system using active impedance estimation," in Proc. 2010 IEEE Energy Conversion Congress and Exposition Conf, pp. 3050-3054

[4] D. Thomas, M. Sumner, D. Coggins, X. H. Wang, J. Wang, and L. Geertsma, "Fault location for DC marine power system," in Proc. 2005 IEEE. Electric Ship Technologies Symposium Conf, pp. 456-460.

[5] M. Dewadasa, A. Ghosh and G. Ledwich, "Fold back current control and admittance protection scheme for a distribution network containing distributed generators," IET Gener Transm \& Distrib, Vol.4, pp.952-962, August, 2010.

[6] A. J. Urdaneta, R. Nadira and L. G. Jimenez, "Optimal coordination of directional over-current relays in interconnected power systems," IEEE Trans. Power Delivery, vol. 3, pp. 903-911, July. 1988.

[7] W. Ei-khattam and T. S. Sidhu, "Resolving the impact of distributed renewable generation on directional overcurrent relay coordination a case study," IET Gener Transm \& Distrib, Vol.3, pp.415-425, December 2009.

[8] H. Y. Li, E. P. Southern, P. A. Crossley, S. Potts, S. D. A. Pickering, B. R. J. Caunce and G. C. Weller, "A new type of differential feeder protection relay using the Global Positioning System for data synchronization," IEEE Trans. Power Delivery, vol. 12, pp. 1090-1099, July. 1997.

[9] K. Kangvansaichol and P. A. Crossley, "Multi-zone differential protection for transmission networks," in Proc. 2004 IEE Developments in Power System Protection Conf, pp. 315-320.

[10] R. M. Cuzner and G. Venkataramanan, "The status of DC micro-grid protection," in Proc. 2008 IEEE Industry Applications Society Meeting Conf, pp. 1-8.
[11] S. Fletcher, I. M. Elders, P. Norman, S. Galloway, C. Booth, and G. Burt, "The impact of incorporating skin effect on the fault analysis and protection system performance of DC marine and aerospace power systems," in Proc. 2010 IET Developments in Power System Protection (DPSP) Conf, pp. 1-5

[12] S. Fletcher, P. Norman, S. Galloway, and G. Burt, "Mitigation against overvoltage on a DC marine electrical system," in Proc. 2009 IEEE Electric Ship Technologies Symposium Conf, pp. 420-427

[13] J. Ciezki, and A. Robert, "Selection and stability issues associated with a navy shipboard DC zonal electric distribution system," IEEE Trans. Power Delivery, vol. 15, pp.665-669, July. 2000. 2000, 15, (2), pp. 665-669

[14] T. Takagi, Y. Yamakoshi, J. Baba, K. Uemura and T. Sakaguchi, “A new algorithm of an accurate fault location for EHV/UHV transmission lines part I - Fourier Transformation method," IEEE Trans. Power Apparatus and system, vol.100, pp. 1316-1323, Match, 1981.

[15] T. Takagi, Y. Yamakoshi, M. Yamaura, R. Kondow and T.matsushima, "Development of a new type fault locator using the one-terminal voltage and current data,", "IEEE Trans. Power Apparatus and system, vol.101, pp. 1116-1123, August, 1982.

[16] A. T. Johns and S. Jamali, "Accurate fault location technique for power transmission lines," IET Gener Transm \& Distrib, Vol.37, pp.395-402, November, 1990.

[17] C. L. Chuang, J. A. Jiang, Y. C. Wang, C. P. Chen, and Y. T. Hsiao, "An adaptive PMU-based fault location estimation system with a faulttolerance and load-balancing communication network," in Proc. 2007 IEEE Lausanne Power Tech Conf, pp. 1197-1202

[18] E. Schweitzer, "Evaluation and development of transmission line faultlocating techniques which use sinusoidal steady-state information," in Proc. 2007 Ninth Annual Western Protective Relay Conf, pp. 93-98.

[19] A. L. Dalcastagne, S. N. Filho, H. H. Zurn and R. Seara, "A twoterminal fault location approach based on unsynchronized phasors," in Proc. 2006 IEEE Power System Technology Conf, pp.1-7.

[20] A. L. Dalcastagne, S. N. Filho, H. H. Zurn and R. Seara, "An iterative two-terminal fault-location method based on unsynchronized phasor,"," IEEE Trans. Power Delivery, vol.23, pp.665-669, October. 2008.

[21] D. Thomas, C. Christopoulos, Y. Tang, P. Galen, and J. Stokoe, "Single ended travelling wave fault location scheme based on wavelet analysis," in Proc. 2004 IEE Developments in Power System Protection Conf, pp. $196-199$.

[22] P. A. Crossley and P. G. Mclaren, "Distance Protection Based on Travelling Waves," IEEE Trans. Power Apparatus and system, vol.102, pp. 2971-2983, August, 1983.

[23] A. V. Oppenheim and R. W. Schafer, Discrete-Time Signal Processing, New York: Upper Saddle River Prentice-Hall Press, 1999, pp. 467-471.

[24] M. Sumner, B. Palethorpe, and D.W.P Thomas, "Impedance measurement for improved power quality-part 1: the measurement technique," IEEE Trans. Power Delivery, Vol.19, pp. 1442-1448, March, 2004

[25] M. Sumner, B. Palethorpe, and D.W.P Thomas, "Impedance measurement for improved power quality-part 2: a new technique for stand-alone active shunt filter control," IEEE Trans. Power Delivery, Vol.19, pp. 1457-1463, March, 2004

[26] S. J Miller, "The method of least squares," Mathematics Department Brown University Providence, RI 02912

[27] Math Works, T., Matlab Help. 7.2.0.232(R2006a) ed. December, 2006

[28] Z. He, J. Zhang, W. Li and X. Lin, "Improved fault-location system for railway distribution system using superimposed signal," IEEE Trans on Power Delivery, VOL. 25(3), pp.1899-1911, July, 2010.

[29] Y. Bai, W. Cong, J. Li, L. Ding, Q. Lu and N. Yang, "Single phase to earth fault location method in distribution network based on signal injection principle," Electric Utility Deregulation and Restructuring and Power Technologies (DRPT), pp.204-208. 2011.

[30] P. Toman, J. Orsagova and D. Topolanek, "Location of the Earth Faults in MV Compensated Networks," Developments in Power System Protection(DPSP), pp.327-331, 2008

[31] A. Dan and D. Raisz, "Comparison of different methods for earth fault location in compensated networks," Electric Power Quality and Supply Reliability Conference (PQ), pp. 237-242, 2010.

[32] R. Razzaghi, G. Lugrin, H. Manesh, C. Romero, M. Paolone, F. Rachidi, "An efficient method based on the electromagnetic time reversal to locate faults in power networks," IEEE Transaction on Power Delivery, pp.1663-1673.Volume:28(3), 2013 